\title{
Degree of processing and nutritional value of children's food products
}

\author{
Célia Regina Barbosa de Araújo ${ }^{1,2, *} \odot$, Karla Danielly da S Ribeiro ${ }^{2}{ }^{\circ}$, \\ Amanda Freitas de Oliveira ${ }^{2}$, Inês Lança de Morais ${ }^{3}$, João Breda ${ }^{4}$, Patrícia Padrão ${ }^{1,5}$ \\ and Pedro Moreira ${ }^{1,5,6}$ \\ ${ }^{1}$ Faculdade de Ciências da Nutrição e Alimentação, Universidade do Porto, Porto, Portugal: ${ }^{2}$ Departmento de \\ Nutritição, Universidade Federal do Rio Grande do Norte, Avenida Senador Salgado Filho, 59.078-970, Natal, RN, \\ Brazil: ${ }^{3}$ World Health Organization Regional Office for Europe, Copenhagen, Denmark: ${ }^{4}$ Division of Country Health \\ Policies and Systems, World Health Organization Regional Office for Europe, Copenhagen, Denmark: ${ }^{5}$ EPI Unit, \\ Instituto de Saúde Pública, Universidade do Porto, Porto, Portugal: ${ }^{6}$ Centro de Investigação em Actividade Física, \\ Saúde e Lazer, Universidade do Porto, Porto, Portugal
}

Submitted 18 February 2021: Final revision received 18 August 2021: Accepted 3 September 2021: First published online 8 September 2021

\begin{abstract}
Objective: This study aimed to characterise the availability, the nutritional composition and the processing degree of industrial foods for 0-36-month-old children according to the neighbourhoods affluence.

Design: A cross-sectional exploratory study.

Setting: All food products available in retail stores for children aged 0-36 months were analysed. Data collection took place in two neighbourhoods, comparing two different sociodemographic districts (high $v$. low per capita income), Campanhã and Foz do Douro in Porto, Portugal.

Participants: A total of 431 commercially processed food products for children aged $0-36$ months which are sold in 23 retail stores were identified. Food products were classified according to their processing degree using the NOVA Food Classification System.

Results: For NOVA analysis, of the 244 food products that were included 82 $(33.6 \%)$ were minimally processed, 25 (10.2\%) processed and $137(56 \cdot 1 \%)$ ultra processed. No food product was classified as a culinary ingredient. The products included mostly cereals, yogurts, prevailed in high-income neighbourhoods for the 0-6-month-old group. It was observed that some categories of ultra-processed food (UPF) presented higher amounts of energy, sugars, saturated fat and salt than unprocessed/minimally processed products.

Conclusions: The high availability of UPF offered for 0-36-month-old children should be considered when designing interventions to promote a healthy diet in infancy.
\end{abstract}

\section{Keywords \\ Children's food \\ Product labelling \\ Nutritional composition Ultra-processed foods}

Early nutrition is an important factor that impacts the development of eating behaviour, food preferences, growth and health, particularly the risk of non-communicable diseases $^{(1)}$. The complex and controversial debate on the role of food processing as the main driver of the quality of the diet and the nutritional adequacy of children's food needs to be clarified when considering that industrial foods can be extensively used during the complementary feeding period and in early childhood ${ }^{(2)}$.

Recent population-based dietary studies indicate that diets rich in ultra-processed foods (UPF), increasingly common worldwide, are extremely unbalanced in nutritional terms, suggesting that the UPF contribution largely determines the overall nutritional quality of contemporary diets ${ }^{(3)}$. Given this scenario, investigating information on nutrient profiles and processing characteristics of industrial food and beverages targeted at children is necessary. In addition, collecting data on processed children's food products is an important tool for monitoring nutritional composition, assessing the need for reformulation of nutritional products or other quality control measures, such as consumer-friendly labelling or nutrient profiling tools, and evaluating the impact of any future strategies to improve industrialised foods offered to children. 
The goal of this study was to characterise the availability, nutritional composition and other labelling information of food for 0-36-month-old children, according to their processing degree, comparing two sociodemographic districts (high $v$. low per capita income) in Porto, Portugal.

\section{Methods}

\section{Study design}

This is a cross-sectional quantitative study conducted in Porto, Portugal, from November 2018 to February 2019, in which a protocol developed by the WHO - Europe was applied to identify commercial baby foods available in retail settings and collect information on the type of food, target age group, nutritional composition, labelling, visual information and health and nutrition claims ${ }^{(4)}$. Data were collected using an electronic questionnaire administered through an existing android-based application, KoBoCollect ${ }^{(5)}$. We analysed all food products available at retail stores in the eligible geographic area and targeted at 0-36-month-old children. Data collection took place in two neighbourhoods - Campanhã and Foz do Douro where, according to the National Statistics Institute and Porto City Council, a greater contrast in per capita income is observed ${ }^{(6)}$. The commercial establishments surveyed were classified according to the Portuguese Yellow Pages $^{(7)}$. We identified twenty-eight establishments, although one had been closed, three did not allow data collection and one was in a region of difficult access. Finally, data collection was conducted by the first author of the manuscript in the remaining twenty-three establishments.

\section{Inclusion/exclusion criteria}

All retail stores that sell food were visited (supermarkets, mini markets, convenience shops and pharmacies), and all food products labelled as suitable for ages 0-36 months were registered and had their label information collected.

Food products targeted at 0-36-month-old children were selected according to the following criteria: (a) Labelled with the words 'baby', or 'small child'; (b) Labelled as suitable or recommended for introduction under the age of 36 months; (c) Labelled with the image of a child who appears to be under 36 months old or bottle-fed; or (d) Presented in any other way as suitable for children under 36 months old using a strategy other than labelling (e.g. posters, temporary sales zones or fairs, in-store, specially created for this age group).

Most products were found in the non-perishable food section of the baby and toddler food aisle. Some were also found in the store's refrigerated or frozen food aisles.

Products which did not fall within this scope were excluded from this study, as well as those that were not specifically targeted at 0-36-month-old children; beside vitamin and mineral food supplements, whether consumed as tablets/drops or added to food at home (e.g. home fortification products, such as powdered micronutrients).

\section{Collected data and categorisation of food groups}

Food products included breastmilk substitutes, formulas, transition products, porridge, main meals, yogurt, fruit and vegetable puree, cookies and crackers, chips, smoothies and other drinks. All food products were classified according to the NOVA classification into minimally processed, processed and ultra processed ${ }^{(8)}$.

Minimally processed foods (Group 1) were those that were altered only by removing inedible or unwanted parts, drying, crushing, grinding, fractionating, filtering, roasting, boiling, pasteurisation, refrigeration, freezing, placing in containers, vacuum packaging or non-alcoholic fermentation, without adding any other ingredients.

Processed foods (Group 2) included those industrialised preparations with added sugar, oils, salt or other types of cooking ingredients (other fats, etc.).

Finally, UPF (Group 3) were identified when food substances never or rarely used were found among the list of ingredients. Some of those substances include different types of sugars (fructose, high fructose corn syrup, 'fruit juice concentrates', inverted sugar, maltodextrin, dextrose, lactose), modified oils (hydrogenated or inter-esterified oils), protein sources (hydrolysed proteins, soy protein isolate, gluten, casein, whey protein and 'mechanically separated meat'), as well as additive cosmetics used for aroma, flavour enhancers, dyes, emulsifiers, among other applications ${ }^{(8)}$. Health claims were allocated to the following: (a) helps with growth and development; (b) strengthens the immune system; (c) improves cognitive skills; (d) helps to reduce/prevents allergies; (e) nutritionally complete and (f) other.

We obtained the products' nutritional composition information from the values declared on labels, per $100 \mathrm{~g}$ and/or per serving, for energy (kilocalories and/or kilojoules), protein, fat (total and saturated fat), carbohydrates (total and sugars) and salt. For that analysis, baby formulas and breast milk substituted were excluded since they are specifically formulated to meet children's daily nutritional needs. The following information was also collected: product name, brand, target age group and the photographic record of all parts of the product. The visual information was recorded for products which contained cartoons, pictures of infants or young children, pictures of mothers, pictures of ingredients and claims of endorsement by a professional body and others.

\section{Statistical analysis}

We used the SPSS Statistics 25 software for statistical analysis. For the independent variables, the Kruskal-Wallis test was used to assess the level of significance of the total energy value contribution variable in relation to the products' processing degree (NOVA), using only non-repeated 
foods. The differences between categorical variables according to the processing classification were calculated using the $\chi^{2}$ test. We calculated the nutritional information using averages (per $100 \mathrm{~g}$ and per serving) and compared them according to the processing degree, which was only considered significant when $P<0.05$.

\section{Results}

Out of the 431 items assessed in 23 establishments, 305 items $(71 \%)$ were available in the lower-income neighbourhood (12 establishments) and 126 items (29\%) in the higher-income neighbourhood (11 establishments) (Table 1). When comparing the two neighbourhoods, we observed that in the low-income neighbourhood there was a higher proportion of products in the Groups 1 and 2 , while products categorised in Group 3 were more often found in high-income neighbourhoods $(P=0.026)$. In general, the most often found food in the ultra-processed category were cereals $(47.7 \%)$, followed by breast milk substitute (27.1\%); regarding processed foods, meat/fishbased food prevailed (82.1\%). Cookies/wafer/crisps $(2 \cdot 3 \%)$ were found only in the UPF category, as well as juice/smoothie/tea/other drinks (3.9\%). Although fruit/ vegetable purees were the only products present in all categories, they appeared mostly in the minimally processed group (79.4\%). Out of the 311 non-repeated food products, $71.0 \%$ were ultra processed (Group 3), followed by $22.5 \%$ of minimally processed (Group 1 ) and $6.5 \%$ of processed (Group 2), with the same sequence of availability in both neighbourhoods. No food product was classified as a culinary ingredient.

Table 2 presented the nutritional information of the 244 food products by processing degree category (NOVA), in which $82(33.6 \%)$ were minimally processed, 25 (10.2\%) processed and 137 (56.1\%) ultra processed, since baby formulas and breast milk substitutes were excluded from the analysis. There was a significant difference in the serving sizes, energy, simple sugar, saturated fat and salt of the food products according to the processing level (NOVA). The UPF category presented higher energy per $100 \mathrm{~g}$ in the groups cereal/porridge, fruit/vegetable purée and yogurt or yogurtrelated products, than these same groups in the unprocessed or minimally processed category, while saturated fat and salt were higher in the groups cereal/porridge and yogurt or yogurt-related products. Fruit and vegetable purées and yogurt or yogurt-related products were groups that presented higher amounts of simple sugar. Some ultra-processed cereals/porridges presented more than the double of simple sugar than minimally processed ones.

When analysing the other information on the labels (Table 3), visual information was present in all the products ( $n$ 431). We verified the presence of health claims in all three categories. All products in Group 1 presented claims such as relief of colic and constipation, antiregurgitation, contributes to the baby's visual development, among others. The labels which claimed 'no added sugar' belonged to the majority $(60.8 \%)$ of products in the Group 1, and to only $14.3 \%$ of the Group 2, and $29.4 \%$ of the Group 3. The 'gluten free' claim predominated in the Group 2 (50\%), followed by the products in Group 1 $(37 \cdot 1 \%)$. Likewise, the 'lactose free' claim was more often observed in the Group 2 (17.9\%), followed by products in the Group 1 (6.2\%). The claim 'no added salt' was more frequent in the Group 2, while 'micronutrient enrichment' claims were more frequently observed in the Group 3, in which $49.7 \%$ of the products were enriched with vitamins and $56.9 \%$ were enriched with minerals. In this study, it was observed that the expression 'nutritionally complete' was used in $886 \% \mathrm{UPF}$, which is related to age-appropriated nutritional products designed to meet the needs of infants.

\section{Discussion}

A remarkable aspect of this research is that the UPF group was the one most prevalent in both studied locations, and its distribution varied according to the income status of both neighbourhoods, with a significantly higher prevalence in the high-income neighbourhood $(80.2 \%$, rather than $67 \cdot 2 \%$ in the low-income neighbourhood). In the lowincome neighbourhood, there was a large commercial food distribution area, while in the high-income neighbourhood, there were several small stores. This discrepancy in the typology of stores may contribute to explain the differences in availability between the neighbourhoods. We also observed that the products in the Group 1 were in a greater percentage in the low-income neighbourhood when compared to the other one. It also became evident that the servings/packages of products pertaining to the Group 1 were larger in the low-income neighbourhood. This may be due to the fact that it was in the low-income neighbourhood that the largest department store identified during the study was located. Such store had the biggest variety of products, including the unprocessed/minimum processed foods. In contrast, we observed UPF in greater availability in the neighbourhood with the higher income. According to Monteiro et al., the aggressive and sophisticated marketing of these foods enhances their 'advantages' (convenience, brand, price) over unprocessed or minimally processed foods, which possibly leads to greater availability of sale and, consequently, consumption ${ }^{(8)}$. Parents and/or caregivers in the high-income areas may choose UPF for practical reasons, or simply because they are more available.

Monteiro et al., back in 2013, evidenced that ultra-processed products were already in the domain or supply chain of food in high-income countries and their consumption was being quickly assessed in the middle-income ones ${ }^{(9)}$. In Australia, a recent study by Machado et al. also found a higher availability of UPF than the other food groups for 
Table 1 Availability of children's food products in low-income (Campanhã) and high-income (Foz) neighbourhoods, according to processing degree ( $n$ 431, available for collection)

\begin{tabular}{|c|c|c|c|c|c|c|c|}
\hline \multirow{2}{*}{$\frac{\text { Processing type }}{\text { Group } 1 \text { unprocessed or minimally processed foods }}$} & \multicolumn{2}{|c|}{ Total $n 431$} & \multicolumn{2}{|c|}{$\begin{array}{c}\text { Low income } n \\
305(70 \cdot 8 \%)\end{array}$} & \multicolumn{2}{|c|}{$\begin{array}{c}\text { High income } n \\
126(29.2 \%)\end{array}$} & \multirow[t]{2}{*}{$P$ value* } \\
\hline & 97 & 22.5 & 78 & $25 \cdot 6$ & 19 & $15 \cdot 1$ & \\
\hline Cereal/porridge & 12 & $12 \cdot 4$ & 7 & $9 \cdot 0$ & 5 & $26 \cdot 3$ & 0.026 \\
\hline Fruit/vegetable purée & 77 & $79 \cdot 4$ & 65 & 83.3 & 12 & 63.2 & \\
\hline Meat- or fish-based meal & 1 & 1.0 & 0 & 0.0 & 1 & $5 \cdot 3$ & \\
\hline Yogurt or yogurt-related product & 6 & $6 \cdot 2$ & 6 & $7 \cdot 7$ & 0 & 0.0 & \\
\hline Other & 1 & 1.0 & 0 & 0.0 & 1 & $5 \cdot 3$ & \\
\hline Group 2 processed foods & 28 & 6.5 & 22 & $7 \cdot 2$ & 6 & 4.8 & \\
\hline Meat- or fish-based meal & 23 & $82 \cdot 1$ & 17 & $77 \cdot \overline{3}$ & 6 & 100 & 0.026 \\
\hline Fruit/Vegetable purée & 2 & $7 \cdot 1$ & 2 & $9 \cdot 1$ & 0 & 0.0 & \\
\hline Follow-on formula/growing up-milk & 1 & $3 \cdot 6$ & 1 & 4.5 & 0 & 0.0 & \\
\hline Breast milk substitute & 1 & $3 \cdot 6$ & 1 & 4.5 & 0 & 0.0 & \\
\hline Soup & 1 & $3 \cdot 6$ & 1 & 4.5 & 0 & 0.0 & \\
\hline Group 3 ultra-processed foods & 306 & $71 \cdot 0$ & 205 & $67 \cdot 2$ & 101 & $80 \cdot 2$ & \\
\hline Cereal/porridge & 146 & $47 \cdot 7$ & 93 & $45 \cdot \overline{4}$ & 53 & $52 \cdot \overline{5}$ & 0.026 \\
\hline Fruit/vegetable purée & 19 & $6 \cdot 2$ & 17 & 8.3 & 2 & $2 \cdot 0$ & \\
\hline Juice/smoothie/tea/other drinks & 12 & $3 . \overline{9}$ & 6 & 2.9 & 6 & 5.9 & \\
\hline Follow-on formula/growing up-milk & 13 & 4.2 & 11 & 5.4 & 2 & $2 \cdot 0$ & \\
\hline Breast milk substitute & 83 & $27 \cdot 1$ & 48 & $23 \cdot 4$ & 35 & 34.7 & \\
\hline Yogurt or yogurt-related product & 23 & 7.5 & 22 & $10 \cdot 7$ & 1 & 1.0 & \\
\hline Biscuits/wafers/crisps & 7 & $2 \cdot 3$ & 5 & 2.4 & 2 & $2 \cdot 0$ & \\
\hline Otherf & 3 & 1.0 & 3 & 1.5 & 0 & 0.0 & \\
\hline
\end{tabular}

${ }^{\star}$ Chi Square Test, $P$ value for the comparison between low- and high-income neighbourhood.

†Products for specific purposes (e.g. feed thickener, snacks, supplements).

Table 2 Children's food products available in Porto, according to the degree of processing and nutritional information ( $n$ 244)

\begin{tabular}{|c|c|c|c|c|c|c|c|c|c|c|}
\hline \multirow[b]{4}{*}{ Degree of processing/food type } & \multirow{4}{*}{$\frac{\text { Serving }(\mathrm{g})}{\text { Mean }}$} & \multirow{4}{*}{$\frac{\text { Packing }(\mathrm{g})}{\text { Mean }}$} & \multirow{2}{*}{\multicolumn{2}{|c|}{ Energy (kcal) }} & \multicolumn{6}{|c|}{ Contribution to total energy value (\%) } \\
\hline & & & & & \multicolumn{2}{|c|}{$\begin{array}{c}\text { Carbohydrates } \\
(\%)\end{array}$} & \multirow{3}{*}{$\frac{\text { Protein }(\%)}{\text { Mean }}$} & \multicolumn{2}{|c|}{ Fat $(\%)$} & \multirow{2}{*}{$\frac{\text { Salt }}{g / 100 \mathrm{~g}}$} \\
\hline & & & $/ 100 \mathrm{~g}$ & /serving & Total & Sugars & & Total & SFA & \\
\hline & & & Mean & Mean & Mean & Mean & & Mean & Mean & Mean \\
\hline \multicolumn{11}{|c|}{ Group 1 - unprocessed or minimally processed foods, $n 82$ (34 \%) } \\
\hline Low-income $(n 63)$ & 80 & 234 & 95 & 136 & 87.5 & $72 \cdot 1$ & $5 \cdot 2$ & $6 \cdot 3$ & 1.9 & 0.36 \\
\hline High-income ( $n$ 19) & 25 & 189 & 145 & 161 & $86 \cdot 8$ & $47 \cdot 6$ & $8 \cdot 1$ & $5 \cdot 1$ & 1.9 & 0.22 \\
\hline$P$ value $^{*}$ & 0.025 & 0.360 & 0.15 & 1.00 & 0.768 & 0.214 & 0.001 & 0.798 & 0.928 & 0.628 \\
\hline Cereal/porridge & 29.5 & 249 & $390 \cdot 4$ & 185 & 81.9 & $12 \cdot 3$ & $11 \cdot 2$ & 9.9 & $2 \cdot 4$ & 0.08 \\
\hline Fruit/vegetable purée & 90 & 212.4 & 62.3 & 57.5 & 93 & 77.9 & $3 \cdot 8$ & 3.2 & 0.7 & 0.02 \\
\hline Meat- or fish-based meal & NF & 190 & 260 & NF & $45 \cdot 8$ & $44 \cdot 3$ & $33 \cdot 8$ & $20 \cdot 6$ & $6 \cdot 9$ & $0 \cdot 10$ \\
\hline Yogurt or yogurt-product & 250 & 300 & 80 & 243 & 63 & $43 \cdot 8$ & 11.9 & $25 \cdot 1$ & $14 \cdot 3$ & 0.09 \\
\hline Other & NF & 190 & 34 & NF & 71 & $11 \cdot 8$ & 23.7 & $5 \cdot 3$ & 0.0 & 0.03 \\
\hline \multicolumn{11}{|c|}{ Group 2 - processed foods, $n 25$ (10\%) } \\
\hline Low income $(n 63)$ & 230 & 347 & 66 & 143 & $53 \cdot 6$ & $48 \cdot 3$ & $15 \cdot 9$ & 30.4 & 8.4 & 0.09 \\
\hline High income ( $n 19)$ & 250 & 227 & 72 & 154 & $50 \cdot 9$ & $48 \cdot 8$ & 19.5 & $29 \cdot 6$ & $7 \cdot 7$ & 0.07 \\
\hline$P$ value $^{\star}$ & 0.480 & 0.182 & 0.102 & 0.380 & 0.861 & 0.090 & 0.070 & 0.365 & 0.815 & 0.438 \\
\hline Meat- or-fish-based meal & 230 & $261 \cdot 2$ & $69 \cdot 3$ & 137 & $50 \cdot 1$ & $8 \cdot 4$ & $19 \cdot 0$ & $30 \cdot 9$ & $7 \cdot 6$ & 0.10 \\
\hline Fruit/vegetable purée & NF & 400 & 51.5 & NF & $92 \cdot 9$ & 74.9 & $3 \cdot 3$ & 3.8 & 1.0 & 0.07 \\
\hline Soup & 250 & 500 & 61 & 152 & $49 \cdot 1$ & 15 & 9.5 & 41.4 & $13 \cdot 3$ & 0.06 \\
\hline \multicolumn{11}{|c|}{ Group 3 - ultra-processed foods, n 137 (56\%) } \\
\hline Low income $(n 63)$ & 81 & 426 & 297 & 192 & $66 \cdot 7$ & $39 \cdot 1$ & 9.8 & $23 \cdot 5$ & $9 \cdot 6$ & 0.10 \\
\hline High income ( $n$ 19) & 68 & 517 & 363 & 166 & 62.9 & 31.9 & $10 \cdot 1$ & $27 \cdot 1$ & 9.9 & 0.52 \\
\hline$P$ value $^{\star}$ & 0.140 & 0.036 & 0.033 & 0.156 & 0.162 & 0.118 & 0.819 & 0.278 & 0.814 & 0.06 \\
\hline Cereal/porridge & 42 & 363 & 423.4 & $204 \cdot 3$ & $73 \cdot 9$ & $27 \cdot 8$ & $11 \cdot 7$ & 14.4 & $5 \cdot 1$ & 0.46 \\
\hline Fruit/vegetable purée & 90 & $182 \cdot 9$ & $64 \cdot 1$ & $57 \cdot 3$ & 91.9 & $76 \cdot 2$ & 4.4 & 3.7 & 0.6 & 0.01 \\
\hline Yogurt or yogurt product & $174 \cdot 0$ & $405 \cdot 0$ & $90 \cdot 3$ & $166 \cdot 8$ & $57 \cdot 4$ & 37.0 & $12 \cdot 8$ & 29.8 & $17 \cdot 1$ & 0.11 \\
\hline Biscuits/wafers/crisps & 6.9 & 111.7 & $442 \cdot 2$ & $30 \cdot 3$ & $70 \cdot 2$ & $14 \cdot 8$ & 5.5 & $24 \cdot 3$ & 9.4 & $0 \cdot 10$ \\
\hline Juice/smoothie/tea/other drinks & NF & $185 \cdot 7$ & $375 \cdot 7$ & NF & $96 \cdot 9$ & 69.6 & 0.60 & 2.5 & $0 \cdot 1$ & 0.06 \\
\hline Other & $30 \cdot 0$ & $445 \cdot 0$ & $293 \cdot 0$ & $150 \cdot 0$ & $66 \cdot 7$ & $19 \cdot 7$ & $5 \cdot 8$ & $27 \cdot 5$ & $8 \cdot 8$ & 0.21 \\
\hline$P$ value ${ }^{\star \star}$ & 0.007 & $<0.001$ & 0.042 & 0.011 & 0.383 & 0.004 & 0.189 & 0.306 & 0.082 & $<0.001$ \\
\hline
\end{tabular}

$\mathrm{NF}=$ none found.

${ }^{*} P$ value for the comparison between neigbourhoods.

${ }^{\star \star} P$ value for the comparison of the total amount of each, serving/packing/nutritional variable between the NOVA categories, Kruskal-Wallis test. 
Table 3 Label information for foods marketed for 0-36-month-old children by type of processing, Porto/Portugal ( $n$ 431, available for collection)

\begin{tabular}{|c|c|c|c|c|c|c|}
\hline \multirow{2}{*}{$\frac{\text { Label info }}{\text { Food type }}$} & \multicolumn{2}{|c|}{$\begin{array}{l}\text { Group } 1 \text { unproc- } \\
\text { essed or minimally } \\
\text { processed foods } \\
(n 97)\end{array}$} & \multicolumn{2}{|c|}{$\begin{array}{l}\text { Group } 2 \text { proc- } \\
\text { essed foods } \\
\quad(n 28)\end{array}$} & \multicolumn{2}{|c|}{$\begin{array}{l}\text { Group } 3 \text { ultra-proc- } \\
\text { essed foods } \\
(n 306)\end{array}$} \\
\hline & & & & & & \\
\hline Cereal/porridge & 12 & $12 \cdot 4$ & 23 & $82 \cdot 1$ & 146 & $47 \cdot 7$ \\
\hline Meat- or fish-based meal & 1 & $1 \cdot 0$ & 17 & 73.9 & - & - \\
\hline Breast milk substitute & - & - & 1 & 3.6 & 83 & $27 \cdot 1$ \\
\hline Yogurt or yogurt-related product & 6 & $6 \cdot 2$ & - & - & 23 & 7.5 \\
\hline Follow-on formula/growing up-milk & - & - & 1 & $3 \cdot 6$ & 13 & $4 \cdot 2$ \\
\hline Other & 1 & 1.0 & - & - & - & - \\
\hline Fruit/vegetable purée & 77 & $79 \cdot 4$ & 2 & $7 \cdot 1$ & 19 & $6 \cdot 2$ \\
\hline Soup & - & - & 1 & $3 \cdot 6$ & - & - \\
\hline Biscuits/wafers/crisps & - & - & - & - & 7 & $2 \cdot 3$ \\
\hline Juice/smoothie/tea/other drink & - & - & - & - & 12 & 3.9 \\
\hline \multicolumn{7}{|l|}{ Age range (months) } \\
\hline $0-6$ & 82 & 84.6 & 22 & $78 \cdot 6$ & 262 & $85 \cdot 3$ \\
\hline$<12$ & 2 & $2 \cdot 1$ & 4 & $14 \cdot 3$ & 10 & $3 \cdot 3$ \\
\hline$>12$ & 3 & 3.1 & 2 & $7 \cdot 1$ & 25 & $8 \cdot 2$ \\
\hline $0-36$ & 10 & $10 \cdot 3$ & - & - & 9 & 3 \\
\hline \multicolumn{7}{|l|}{ Visual information } \\
\hline Cartoons & 25 & $25 \cdot 8$ & 7 & $25 \cdot 0$ & 233 & $76 \cdot 1$ \\
\hline Pictures of infantes or young children & 13 & 13.4 & 7 & $25 \cdot 0$ & 27 & $8 \cdot 8$ \\
\hline Pictures of mothers & 0 & - & - & - & 5 & $1 \cdot 7$ \\
\hline Pictures of ingredients & 59 & $60 \cdot 8$ & 14 & $50 \cdot 0$ & 34 & $11 \cdot 1$ \\
\hline Claimed endorsement by professional body & - & - & - & - & 1 & 0.3 \\
\hline Other & - & - & - & - & 6 & $2 \cdot 0$ \\
\hline \multicolumn{7}{|l|}{ Health claims } \\
\hline Growth/development & - & - & 2 & $7 \cdot 1$ & 4 & $1 \cdot 3$ \\
\hline Immune system & - & - & 2 & $7 \cdot 1$ & 1 & 0.3 \\
\hline Cognitive abilities & - & - & 2 & $7 \cdot 1$ & 11 & $3 \cdot 6$ \\
\hline Prevent allergies & - & - & 2 & $7 \cdot 1$ & 2 & 0.7 \\
\hline Nutritionally complete & - & - & - & - & 17 & $5 \cdot 6$ \\
\hline Other & 97 & 100 & 26 & $92 \cdot 9$ & 271 & $88 \cdot 6$ \\
\hline \multicolumn{7}{|l|}{ Nutrient claims } \\
\hline Fortified with vitamins & 41 & $42 \cdot 3$ & 2 & $7 \cdot 1$ & 152 & $49 \cdot 7$ \\
\hline Fortified with minerals & 6 & $6 \cdot 2$ & - & - & 174 & $56 \cdot 9$ \\
\hline Gluten free & 14 & $37 \cdot 1$ & 14 & 50 & 79 & $25 \cdot 8$ \\
\hline No cow's milk protein & 8 & $8 \cdot 2$ & 8 & $28 \cdot 6$ & 16 & $5 \cdot 2$ \\
\hline No added sugar & 59 & $60 \cdot 8$ & 4 & $14 \cdot 3$ & 90 & 29.4 \\
\hline No added salt & 1 & 1 & 15 & $53 \cdot 6$ & 1 & 0.3 \\
\hline Lactose free & 6 & $6 \cdot 2$ & 5 & 17.9 & 15 & 4.9 \\
\hline Natural & 12 & $12 \cdot 4$ & 5 & $17 \cdot 9$ & 3 & 1 \\
\hline
\end{tabular}

Note: the same food product may me classified in more than one item within a label category.

consumers older than 2 years (UPF represented $42 \%$, while minimally processed were $35.4 \%$, and processed foods were $15.8 \%)^{(10)}$. Processes and ingredients that are used to make UPF are designed to create highly profitable products (low-cost ingredients, long shelf life, emphatic brand), convenient (ready to eat), highly palatable products that can displace all other NOVA food groups, especially unprocessed or minimally processed foods. According to Lawrence and Baker, the NOVA food classification system, with its identification and definition of UPF, or what has been mostly applied in the scientific literature ${ }^{(11)}$; it is also easily incorporated into the messages and then reproduced. Therefore, NOVA classification is largely known, useful for the public and used in epidemiological studies ${ }^{(12)}$.

Aiming at providing an accurate analysis of the food products studied in this research, besides classifying them according to NOVA, their nutrient composition was also evaluated. We observed that some categories of the UPF presented higher amounts of energy, sugars, saturated fat and salt than unprocessed/minimally processed foods, suggesting inferior quality for these food components. However, some authors point out some limitations for this methodology. According to Gibney et al. ${ }^{(13)}$ in NOVA, the reference for salt, sugar and fats lacks standards by the amount in grams, by serving/size or by energy; the reference on food additives presents particular challenges since they may be legally allowed in food, as the case of the ones allowed in Follow-on formulas/growing up-milk, as well as in Breast milk substitutes, products which were in this study and were observed to be a part of the processed group, and even more often in the ultra-processed group. We excluded such products from the nutritional analysis for being specifically formulated to meet children's daily nutritional needs. 
In relation to the contribution of food according to the category of processing for total energy value, we observed that the UPF were the most energetically dense. Some studies have shown that diets based on this category of foods exhibit negative nutritional characteristics such as being energy dense, and low fibre ${ }^{(14,15)}$, with high levels of free and added sugars, saturated and trans fats, which can have a negative impact on health. In fact, UPF are accused of being positively associated with obesity ${ }^{(16)}, \mathrm{CVD}^{(17)}$ and other chronic non-communicable diseases; moreover, UPF may contribute to the prevalence of autoimmune diseases, such as type 1 diabetes, coeliac disease ${ }^{(14)}$, depression and mortality from all causes ${ }^{(18)}$.

Considering that the risk of chronic disease begins early in life, with important health consequences of feeding behaviours in infancy, lower intakes of saturated fats, added sugars and sodium should be preserved in early childhood ${ }^{(19)}$. Additionally, higher values of salt were found in the Group 3, supporting a study by Srour, which reported that these foods usually have a higher content of salt, total fat, saturated fat, added sugar and energy density ${ }^{(17)}$. In Taiwan, more than $50 \%$ of processed complementary foods carried high levels of sugar and more than $20 \%$ carried high levels of sodium ${ }^{(20)}$. In Brazil, Louzada et al. showed that UPF contributed to a higher energy density, free sugar and total fat, saturated and trans fat, when compared to the group of fresh or minimally processed foods. This fact evidences the possibility of harmful effects that the substitution of fresh or minimally processed foods by other UPF may have ${ }^{(21)}$. As part of a healthy diet, it is also recommended to avoid trans fat ${ }^{(22)}$, but these lipids were not assessed because they are not reported in the nutrition labelling of food products.

In Brazil, a recent study audited 5620 packaged foods available in several major Brazilian supermarket chains and collected information from the nutritional tables on the packaging and labels that compare the nutrient content between foods targeted at children and for other consumers $^{(23)}$. Children's dairy products and meat-based foods exhibited a higher carbohydrate content when compared to similar non-children's foods.

The great majority of foods that are classified as ultra processed in this study were cereals/porridges. Baby cereals are one of the first foods offered during complementary feeding and can play an important role in the complementary feeding period and in the early stage of life, providing the baby with energy, macronutrients, vitamins, minerals, bioactive compounds and non-digestible carbohydrates that stimulate the intestinal microbiota. However, its consumption should be avoided by babies younger than 4 months old ${ }^{(24)}$. It is important to note that the processing of children's cereals may include formulation strategies that increase free sugar contents of the products. The European Society for Pediatric Gastroenterology, Hepatology and Nutrition states that no sugar should be added to foods and free sugars should be minimised or avoided ${ }^{(25)}$, while $\mathrm{WHO}$ recommends children and adults to reduce their daily free sugar intake to less than $10 \%{ }^{(26)}$. The American Heart Association recommends that children under 2 years old should avoid adding sugars at all ${ }^{(27)}$.

In this study, the availability of the three food categories for the age group from 0 to 6 months was high. In Portugal, most children start complementary feeding between 4 and 5 months old, and approximately one-third were breastfed for less than 4 months ${ }^{(28)}$. This finding is particularly relevant because it is recommended for children at this age to be exclusively breastfed. This trend to make industrial foods available for such early ages follows the results of other European cities, showing a significant proportion of products ( $28 \%$ to $60 \%$ ) being marketed as suitable for babies under 6 months old ${ }^{(4)}$. According to WHO, foods should not be marketed as suitable for children under 6 months old ${ }^{(29)}$. A document that guides the marketing of food for babies and young children was drafted, making it clear that the messages must include a statement on the importance of continued breastfeeding for up to 2 years of age or more, and must specify the age of introduction of such food (not less than 6 months old) ${ }^{(29)}$. However, several studies ${ }^{(30,31)}$ found that the introduction of UPF occurred early in the children's diet, before 12 months old, and that $70.6 \%$ of them may already have consumed instant noodles ${ }^{(30)}$. Sometimes it is also mentioned that labels in formulas for healthy infants could confuse customers as to the far higher quality of breast milk $^{(32)}$. In this study, we observed that the expression 'nutritionally complete' was used in UPF, which is related to age-appropriated nutritional products designed to meet the needs of infants.

This study, being observational and cross-sectional, has as its main limitation the analysis of only a certain period of time. Nevertheless, it allows to speculate a pattern of consumption, considering the availability of foods to be purchased. Another limitation is related to the two neighbourhoods selected for they are not representative of the low- and high-income conditions, though the authors' intention was to obtain the availability of foods in those areas which would represent the greatest difference in income neighbourhoods of Porto for a better analysis of foods targeted at 0-36-month-old children in both economic extremes.

The WHO recommends the use of low-cost enriched complementary foods as needed, but the promotion of these products should protect breastfeeding and the consumption of different diets based on locally available foods, thus not promoting UPF in general.

FAO calls attention to the importance of public policies and actions in order to protect the production, manufacture, distribution, sale and consumption of healthy foods. This should be aligned with an increase in consumption of minimally processed foods and a decrease in the consumption of UPF considering the relation between these foods and the risk of non-communicable disease ${ }^{(33)}$. As a 
result, this study demonstrates the relevance of research in the children's food scope, specially from 0 to 36 months old, since it contributes with data that allow the mapping of the food products targeted at children. It is recommended, therefore, the development of strategies that promote nutritional education to limit the consumption of UPF. It is worth highlighting that in this study we classified several products in the minimally processed group, which suggests that commercial stimulus of these product should impact the availability of better nutritious quality items for children ${ }^{(34)}$.

Supporting changes and monitoring of the nutrient composition of such products is important to improve commercial foods' nutrient profiles. Food products targeted at children should meet all regional, national and global standards for composition, safety and nutritional quality. It is equally important to develop strategies for promoting breastfeeding, good nutrition and healthy eating habits, since the first 3 years of life are critical for a healthy development. In the future, as part of the nutritional reformulation of food products with an excessive content of fat, salt, sugar or energy, the present analysis may be repeated to monitor the nutrient profiles of industrial foods for 0-36month-old children in Portugal. Although these data cannot be extrapolated for other countries, this assessment is particularly important within the "WHO Global Sodium Benchmarks for Different Food Categories'(35), and the EU framework for National initiatives on Selected Nutrients to address salt, fats, sugars and energy in foods, considering that their implementation should be adjusted to the national context of each Member State ${ }^{(36)}$.

\section{Conclusions}

In this study, we observed that according to the NOVA classification, UPF are the most available foods on the market for 0-36-month-old children, and this prevalence was higher in the neighbourhood with the higher income; the availability of unprocessed or minimally processed foods was proportionally greater in the low-income neighbourhood. Most of the analysed products were aimed at the 0-6-month-old group, and the majority of foods that are classified as ultra processed were cereals/porridges. We highlight that the main nutritional characteristics of the UPF were high energy, sugar, saturated fat and salt.

\section{Acknowledgements}

Acknowledgements: Not applicable. Financial support: This research received no specific grant from any funding agency in the public, commercial or not-for-profit sectors. Conflict of interest: There are no conflicts of interest. Authorship: C.R.B.A. collected the data, participated of the analysis, interpretation of data for the work; drafting the work; final approval of the version to be published; C.R.B.A., P.M., P.P., J.B., K.D.S.R., A.F.O. and I.L.M. also participated of the conception, design of the work; or interpretation of data; review and final approval of the version to be published. Ethics of human subjectparticipation: Not applicable.

\section{References}

1. Agostoni C, Decsi T, Fewtrell M et al. (2008) Complementary feeding: a commentary by the ESPGHAN committee on nutrition. J Pediatr Gastroenterol Nutr 46, 99-110.

2. Araújo C, Ribeiro KD, Padrão P et al. (2019) Industrialized foods in early infancy: a growing need of nutritional research. Porto Biomed J 4, 1-2.

3. Martínez SE, Popkin BM, Swinburn B et al. (2017) The share of ultra-processed foods and the overall nutritional quality of diets in the US: evidence from a nationally representative cross-sectional study. Popul Health Metr 15, 6.

4. World Health Organization (2019) WHO/Europe Studies Find Baby Foods are High in Sugar and Inappropriately Marketed for Babies. http://www.euro.who.int/en/ media-centre/sections/press-releases/2019/whoeuropestudies-find-baby-foods-are-high-in-sugar-and-inappropriatelymarketed-for-babies (accessed October 2019).

5. World Health Organization (2017) Technical Report of the Baby Food Application Project Aiming to Prepare and Conduct a Study on Availability, Composition and Marketing of Commercial Foods in Cooperation with the WHO Regional Office for Europe. WHO Technical Report. Copenhagen, Denmark: WHO Europe.

6. Portuguese National Institute of Statistics (2011). https:// www.ine.pt/xportal/xmain?xpid=INE\&xpgid=ine_cont_inst\& INST $=3585857$ \&xlang=pt (accessed October 2019).

7. Portuguese Yellow Pages (2020) Marketplace list of Porto/ Portugal. http://www.pai.pt/ (accessed October 2019).

8. Monteiro C, Cannon G, Levy R et al. (2019) Ultra-processed foods: what they are and how to identify them. Public Health Nutr 22, 936-941.

9. Monteiro CA, Moubarac J, Cannon G et al. (2013) Ultra-processed products: global dominance. Obes Rev 14, 21-28.

10. Machado PP, Steele EM, Levy RB et al. (2019) Ultra-processed foods and recommended intake levels of nutrients linked to non-communicable diseases in Australia: evidence from a nationally representative cross-sectional study. BMJ Open 9, e029544.

11. Lawrence MA \& Baker PI (2019) Ultra-processed food and adverse health outcomes. BMJ 365, 12289.

12. Monteiro CA, Cannon G, Levy R et al. (2016) NOVA. The star shines bright. World Nutr 7, 1-38.

13. Gibney MJ, Forde CG, Mullally D et al. (2017) Ultra-processed foods in human health: a critical appraisal. Am J Clin Nutr 106, 717-724.

14. Aguayo-Patrón SV \& Calderón de la Barca AM (2017) Old fashioned vs. ultra-processed-based current diets: possible implication in the increased susceptibility to type 1 diabetes and celiac disease in childhood. Foods $\mathbf{6}, 100$.

15. Rocha KF, Araújo CRB, Morais IL et al. (2021) Commercial foods for infants under the age of 36 months: an assessment of the availability and nutrient profile of ultra-processed foods. Public Health Nutr 24(11), 3179-3186.

16. Askari M, Heshmati J, Shahinfar H et al. (2020) Ultraprocessed food and the risk of overweight and obesity: a systematic review and meta-analysis of observational studies. Int J Obes 44, 2080-2091. 
17. Srour B, Fezeu LK, Kesse-Guyot E et al. (2019) Ultraprocessed food intake and risk of cardiovascular disease: a prospective cohort study (NutriNet-Santé). BMJ 365, 11451.

18. Pagliai G, Dinu M, Madarena MP et al. (2020) Consumption of ultra-processed foods and health status: systematic review and meta-analysis. Br J Nutr 125(3), 308-318.

19. Dietary Guidelines Advisory Committee (2020) Scientific Report of the 2020 Dietary Guidelines Advisory Committee: Advisory Report to the Secretary of Agriculture and the Secretary of Health and Human Services. Washington, DC: U.S. Department of Agriculture, Agricultural Research Service.

20. Koo YC, Chang JS \& Chen YC (2018) Food claims and nutrition facts of commercial infant foods. PLoS One 13, e0191982.

21. Louzada MLDC, Martins APB, Canella DS et al. (2015) Ultraprocessed foods and the nutritional dietary profile in Brazil. Rev Saúde Pública 49, 38.

22. Anastácio COA, Oliveira JM, Moraes MM et al. (2020) Nutritional profile of ultra-processed foods consumed by children in Rio de Janeiro. Rev Saúde Pública 54, 89.

23. Machado LM, Rodrigues MV, Nascimento BA et al. (2019) Nutritional composition of Brazilian food products marketed to children. Nutrients $\mathbf{1 1}, 1214$.

24. Klerks M, Bernal MJ, Roman S et al. (2019) Infant cereals: current status, challenges, and future opportunities for whole grains. Nutrients 11, 473 .

25. Development Initiatives (2018) Global Nutrition Report: Shining a Light to Spur Action on Nutrition. Bristol, UK: Development Initiatives.

26. Fewtrell M, Bronsky J, Campoy C et al. (2017) Complementary feeding: a position paper by the European society for paediatric gastroenterology, hepatology, and nutrition (ESPGHAN) committee on nutrition. J Pediatr Gastr Nutr 64, 119-132.
27. World Health Organization (2019) Commercial Foods for Infants and Young Children in the WHO European Region. http:www.euro.who.int/en/health-topics/diseaseprevention/ nutrition/publications/2019/improving-the-nutritional-qualityof-commercial-foods-for-infants-and-young-children-inthe-who-european-region-2019 (accessed January 2020).

28. Lopes C, Torres D, Oliveira A et al. (2017) National Food and Physical Activity Survey IAN-AF 2015-2016: Results Report, University of Porto. www.ian-af.up.pt (accessed January 2020).

29. Maalouf J, Cogswell ME, Bates M et al. (2017) Sodium, sugar, and fat content of complementary infant and toddler foods sold in the United States, 2015. AM J Clin Nutr 105, 1443-1452.

30. World Health Organization (2015) Guideline: Sugars Intake for Adults and Children. Geneva: World Health Organization.

31. Longo-Silva G, Toloni MHDA, Menezes RCED et al. (2015) Ultra-processed foods: consumption among children at day-care centres and their classification according to Traffic Light Labelling system. Rev Nutr 28, 543-553.

32. Relvas GRB, Buccini GS \& Venancio SI (2019) Ultraprocessed food consumption among infants in primary health care in a city of the metropolitan region of SaO Paulo, Brazil. J Pediatr 95, 584-592.

33. Baldani MM, Pascoal GB \& Rinaldi AEM (2018) Labeling and commercial promotion of infant formula marketed in Brazil. Demetra Alimentação Nutr Saúde 13, 413-425.

34. Monteiro CA, Cannon G, Lawrence M et al. (2019) UltraProcessed Foods, Diet Quality, and Health Using the NOVA Classification System. Rome: FAO.

35. WHO (2021) WHO Global Sodium Benchmarks for Different Food Categories. Geneva: World Health Organization.

36. European Union (2018) EU Platform for Action on Diet, Physical Activity and Health on Food Reformulation. http:// ec.europa.eu/health/sites/default/files/nutrition_physical_activity/ docs/2018_foodreformulation_call_en.pdf (accessed January 2020). 